\title{
TRANSAMAZÔNIA: VAMOS AO CAMPO? SENSO COMUM DOUTO E MORTE DO VIVER
}

TRANSAMAZÔNICA: WE GO TO THE FIELDS? THE COMMON SENSE SCHOLAR AND THE DEATH OF LIVING

\author{
Wallace Wagner Rodrigues Pantoja ${ }^{1}$, Herique Heber dos Santos Reis ${ }^{2}$ \\ ${ }^{1}$ Universidade de Brasília (UNB), Brasília, DF, Brasil \\ ${ }^{2}$ Universidade Federal do Pará (UFPA), Belém, PA, Brasil
}

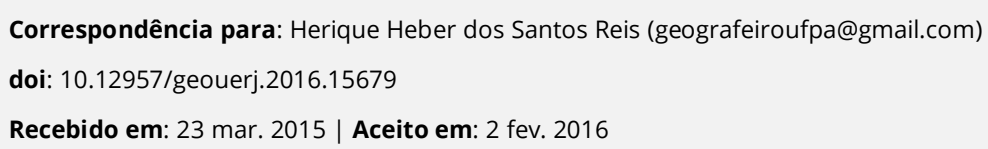

Recebido em: 23 mar. 2015 | Aceito em: 2 fev. 2016

\section{SCREENED BY iThenticate}

\section{RESUMO}

Este artigo é parte de um plano em processo, investigar as representações geograficamente valorizadas acerca da Transamazônica (BR-230) e quais as repercussões destas representações, tanto para os lugares na Transamazônica Paraense, quanto para o saber veiculado pela geografia sobre estes lugares, no plano da educação básica pensada como geopolítica. Nosso objetivo é discutir a relação entre o saber veiculado pelos livros didáticos, chancelados por geógrafos, suas abordagens do espaço amazônico e, especificamente, o espaço transamazônico; confrontado tal saber com a geograficidade dos lugares, para esclarecimento da distância entre representação e vivência geográfica. Partindo do espaço enquanto fenômeno da existência intencionalmente apropriado pelos indivíduos e grupos sociais, metodologicamente, desenvolvemos uma pesquisa bibliográfica dos livros didáticos e uma pesquisa participativa, em processo, nos municípios de Pacajá e Anapu (PA), cortados pela Transamazônica. Como conclusão, evidenciamos o senso comum douto que empobrece as representações geográficas acerca da Transamazônica e, mesmo criticando uma geopolítica que privou homens e mulheres transamazônicos, acaba por refinar tal empobrecimento, suprimindo o vivido em prol de uma representação científica que justifica visões de mundo persistentes sobre o espaço Amazônico.

Palavras-chave: Imaginações Geográficas. Lugar. Educação do/no Campo. Livro Didático. Geopolítica.

\section{ABSTRACT}

This article is part of an plan and process that is to investigate the impact of the geographical representations, valued about the "Transamazônica highway, beyond, which the effect of this representation, for both the Transamazônica places in Pará (Brazil), as to the knowledge propagated by the geography about these places, on the level of basic education, thought as geopolitical. Our goal is to discuss the relationship between the knowledge propagated by textbooks signed by geographers and their approach by the Amazonia space in general and the Transamazonic space in specific, confronted such knowledge with the geograficity places, to understanding the distance between representation and geographic reality. Starting from space as a phenomenon of existence, methodologically, we developed a literature search of the textbooks and a participatory research, still in process, on the cities of Pacajá and Anapu (Pará), crossed by Transamazônica. As conclusion, we observed the common sense scholar, that impoverishes geographically representations of the Transamazônica and, even criticizing the geopolitical which deprived men and women who live in Transamazônica region, ends up refine such impoverishment, killing the real in favor of a scientific representation that justifies persistent worldviews about the Amazon space.

Keywords: Geographical Imaginations. Place. Country Side Education. Textbook. Geopolitics. 


\section{INICIANDO UMA REFLEXÃO DO CAMPO}

O título deste artigo é uma provocação. Objetivamos estabelecer uma discussão entre o livro didático e a realidade educativa da Transamazônica, sobretudo em duas dimensões espaciais: 1) a do lugar de vida no/do campo, centrado na escola, reprodutora ou não do saber bricolado dos livros didáticos; 2) a do território nacional que, via Estado, chancela aos geógrafos a autonomia de definir os livros didáticos através do Plano Nacional do Livro Didático (PNLD), logo, o discurso de (Trans)Amazônia dos livros qualificados pelo pensamento geográfico brasileiro.

O PNLD é uma iniciativa do Ministério da Educação (MEC), para ampliar o acesso de livros e ferramentas didáticas. Além disso, uma equipe de cientistas destacados constrói critérios para editoração dos livros que, se bem avaliados, figuram no Guia dos Livros Didáticos. A equipe de cientistas, neste caso, geógrafos, define quais livros são adequados à escolha dos professores da educação básica, que podem escolher os livros, porém, dentro da lista previamente definida, no caso, o Guia.

Buscamos articular a imaginação geográfica (SAID, 2007) e a imaginação espacial (MASSEY, 2008) (re)produzida, enquanto saber Guiado nos livros ao lugar transamazônico, especialmente à beira da Faixa $^{1}$ (PANTOJA; CORDEIRO, 2012, 2014; PANTOJA, 2015). O objetivo comporta uma duplicidade escalar - como o lugar transamazônico vivencia a educação geográfica e que tipo de saber geográfico sobre a Transamazônica, no plano do território nacional, é apropriado e/ou reproduzido na educação básica, via livros didáticos autorizados.

O caminho que assumimos é fenomenológico, em diálogo com o pensamento existencialista. Acreditamos na incontornável contingência do real, porém, sem perder de vista a estruturação do mesmo, por parte de agregados institucionais que, ao se burocratizar, pretendem gerir o discurso de realidade e de crítica à realidade.

\footnotetext{
1 "A Faixa" é como as famílias que vivem nas vicinais (ou ramais) chamam a Transamazônica. Vicinais ou ramais, são pequenas estradas que começam na Transamazônica e adentram a floresta,ou o que restou dela, do ponto de vista semântico, vicinais quer dizer vizinhança, processo que será explorado em outro texto.
} 
Em termos procedimentais, optamos pela pesquisa de campo, a partir de vivências na formação de professores, singularmente dos municípios paraenses de Pacajá e Anapu; Entrevistas semiestruturadas com professores, estudantes e seus pais, majoritariamente de escolas rurais multisseriadas; leitura dos documentos oficiais do MEC, tanto digitais, disponíveis no site do INEP e impressos, no caso, o Guia.... Somada à interpretação de parte dos livros didáticos qualificados para serem "escolhidos" pelos professores da educação básica. A pesquisa compõe uma das etapas do projeto ), “Geografia e Representação: cartografia da (in)existência entrelugares" ${ }^{2}$, tendo em vista uma análise interpretativa dos significados de (Trans)Amazônia que daí emergem em sua dialética instável (MERLEAU-PONTY, 2012).

Análise, em si, não quer dizer muita coisa a não ser “decompor em partes para estuda-las e recompôlas num todo coerente" (alguém entre Descartes e algum positivista importante deve ter dito isto). Sejamos então mais explícitos: faremos uma análise do saber geográfico em livros didáticos de grande circulação para apreender elementos do que se concebe como Amazônia, mais precisamente, Transamazônica, nos referidos livros, tendo em vista uma intencionalidade, qual seja, um objeto para a consciência, seja a nossa - que o analisamos - e a dos estudantes que, por ventura, possam se apropriar desta concepção.

Aqui temos um limite e uma abertura do método: limite porque não podemos estar dentro da consciência dos estudantes para apreender o que eles intencionam, na sua relação com o "conhecimento (trans)amazônico" que é veiculado pelos livros. Porém, ao direcionar nossa consciência para este "conhecimento" que aparece como fenômeno - podemos construir relações claras que podem dialogar com outras consciências, entre as quais, as dos estudantes e, para fins deste artigo, dos cientistas sociais que se debruçam sobre as mesmas questões. Não se pretende esgotar o que é, mas interpretar o fenômeno para compreender os processos de formação do imaginário geográfico e que repercussões têm no lugar e como o lugar pode reconstituir este mesmo imaginário.

\footnotetext{
${ }^{2}$ Projeto de Doutoramento de Wallace Pantoja, no Programa de Pós-graduação em Geografia (UNB), sob orientação do Prof. Dr. Rafael Sanzio Araújo dos Anjos.
} 
Este texto tem um caráter de crítica à geopolítica da educação, geopolítica dos comitês que definem o que é bom, correto, justo e verdadeiro de ser lido e oficializado pelo Estado - não uma entidade autônoma/autômata, mas em burocratização das relações de saber-poder ao ponto de sua reprodução como norma legitimada (WEBER, 2012). Entre os vários comitês do saber-poder, destacamos aqui o de geógrafos chancelados pelo Estado para guiar, afinal um guia serve para isto, não? Guiar o percurso formativo dos professores ao nível nacional, com resultados aparentemente insuspeitos, tanto para os que educam nas vicinais, quanto para os que educam fora dela, no território nacional. Portanto, é uma proposta de crítica ao Senso Comum Douto que justifica técnica, científica e moralmente, a inexistência de lugares, como os da Transamazônica, nos livros didáticos.

Não esperem um texto comportado, queremos uma geografia malcriada para pensar o lugar da educação do campo e da Transamazônica no plano do cotidiano e do supracotidiano, falamos então de gentes, só que em pontas opostas da escala geográfica e do processo educativo - de um lado os que vivem o espaço-limite; do outro, os que pensam que sabem algo sobre os que vivem lá.

Situações-limites, para Jaspers (1958, pp. 66-67, no original) são:

Situaciones tales como las de que estoy siempre en situación, que no pueda vivir sin lucha y sin sufrimiento, que yo assumo inevitablemente la culpa, que tengo que morir. [...]. Estas situaciones no cambian, salvo solamente en su modo de manifestarse; referidas a nuestra existencia empírica, presentan el carácter de ser definitivas, últimas. Son opacas a la mirada; en nuestra existencia empírica ya no vemos nada más tras ellas. [...] No podemos cambiarlas, sino tan sólo esclarecerlas, sin poder explicar-las ni deducirlas partiendo de otra cosa. Ellas se dan con la existencia empírica miesma.

Refletindo sobre a proposta de Jaspers, os espaços-limite, em nossa concepção, são espaços da existência em confronto, inesperada, a partir de dentro e em situação dos que a vivem, aonde suas ações repercutem enquanto limite da vida, fracasso insuperável (JASPERS, 2011) ou liberdade transcendente, que é como categorizamos o lugar.

\section{ALGUNS DADOS - AQUILO SOBRE O QUE NÃO FALAMOS}


A Geografia é uma ciência em crise ou sem crise, fica ao gosto ${ }^{3}$. O fato é que a ciência produz um saber autorizado e/ou com autoridade. Embora não exista verdade absoluta em ciência... Não é o que dizem por aí? Alguns geógrafos via comitês e equipes de avaliação, definem os parâmetros do que deve e como deve ser ensinado na educação básica, ou seja, o que é verdadeiro para a formação geográfica dos brasileiros.

Em torno de 1,1 bilhão de reais foram gastos na compra de livros didáticos e similares em $2014^{4}$. Investimento que devemos continuar exigindo, porém, a questão aqui é outra. Quatro editoras concentram 71,86\% dos investimentos: Ática, Scipione, Moderna e FTD. Restringindo por componente curricular, na Geografia as coleções de maior alcance são - Projeto Araribá (Moderna), Expedições Geográficas (Moderna) e Projeto Teláris (Ática); com 3,3 milhões, 1,7 milhões e 1,7 milhões de exemplares, respectivamente. Destacamos os livros do $7^{0}$ ano, nos quais a discussão sobre a Amazônia é anunciada mais detidamente, as três coleções perfazem 1.530.000 exemplares.

Tais editoras são as maiores fornecedoras de livros didáticos para a escola pública no território nacional ${ }^{5}$, incluindo a Transamazônica paraense, podemos supor - sem perder de vista a autonomia dos professores - que o imaginário geográfico acerca do campo e, especificamente, o(s) campo(s) transamazônicos, são imaginados através destes livros por grande parte dos estudantes e professores.

\footnotetext{
${ }^{3}$ Argumento algo recorrente nos debates epistemológicos, que atribuem uma interpretação equivocada da realidade a um período de "crise" do saber geográfico, contra o qual uma nova visão, mais esclarecida, se levanta para superação da mesma (Cf. MORAES, 2005; SANTOS, 2002; entre outros). O fato é que, do ponto de vista epistemológico a "família de conceitos geográficos" e os métodos de abordagens, ou crise ou não, são profunda e amplamente desenvolvidos na Geografia Brasileira para trabalhar o temário da disciplina, inclusive, a "coerência conceitual e metodológica" dos livros didáticos do PNDL é um dos tópicos centrais de avaliação.

${ }^{4}$ Fonte: BRASIL-FNDE, 2014. Disponível em: http://www.fnde.gov.br/programas/livro-didatico/livro-didatico-dadosestatisticos, acesso em 13.08.2014.

${ }^{5}$ Há questões, embora não "estritamente geográficas", além da discussão aqui proposta: 1. A receita das editoras com a venda de livros e o lobby junto ao MEC; 2. As exigências que o MEC define para a entrada no Guia.; 3. As relações entre escritores dos livros, as editoras e exigência do mercado editorial na conformação de uma "visão de mundo"; 4. Relações entre a equipe avaliadora e os escritores de livros; 5 . A terceirização da produção dos livros; 6. Os critérios definidos pela equipe de avaliação/construção do guia; Para maiores detalhes dos investimentos do PNLD, Cf. http://www.fnde.gov.br/programas/livro-didatico/livro-didatico-dados-estatisticos, acesso em 20.08.2014.
} 
As imagens a seguir são recorrentes quando o tema é a Transamazônica, em materiais didáticos e de ampla divulgação, quando não há uma imagem de referência, o texto repercute esta imagética:
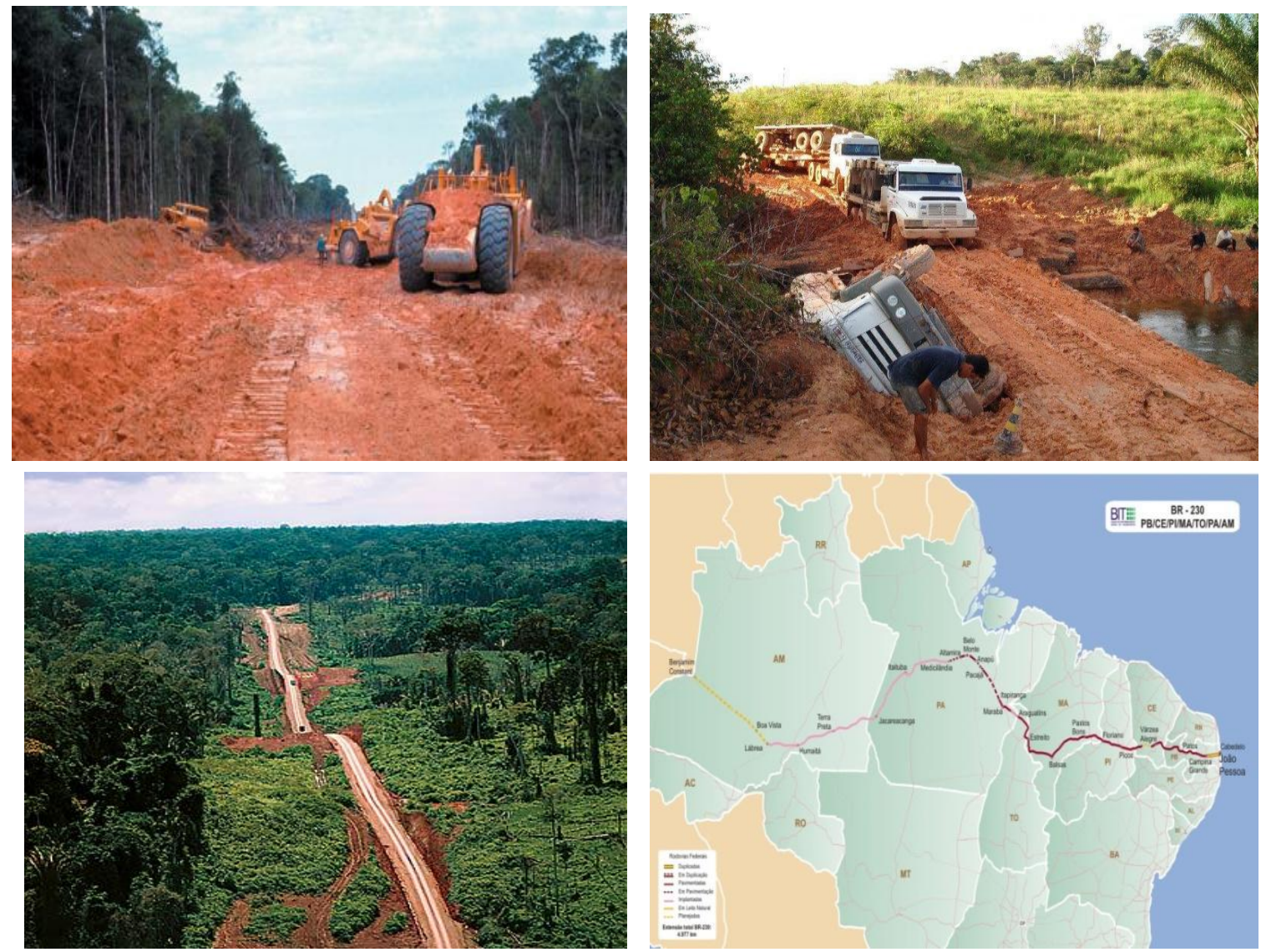

Figura 1. Transamazônica, 1971. Autor: Pierre Monbeig; 2. Transamazônica, 2014. Autor: Gilmar Lira; 3. Visão aérea de trecho da Transamazônica, 2011. Fonte: Revista Veja (on-line), autoria: www.tyba.com.br; 4. Detalhe do Mapa do Brasil demarcando a BR-230 ou Transamazônica (BIT- Banco de Informações e Mapas de

Transportes, 2009).

Tais imagens - não paisagens - são recorrentes em nosso "acervo imaginário" sobre a Transamazônica. Nossas experiências em pesquisa de campo nas vicinais, processos de formação na estrada e diálogo com professores em diversos pontos do Brasil, nos permitem dizer que são as imagens, majoritariamente, identificadoras da Transamazônica!

Para composição de um livro didático, temos clareza do trabalho intelectual envolvido e a impossibilidade - em função da própria escala geográfica privilegiada, a do território nacional - de realizar pesquisas de campo para todos os assuntos. Porém, existe uma variedade gigante de trabalhos realizados e divulgados para consulta e abordagem dos temas que se pretende comunicar em um livro didático. 
Saint-Expéry (2011), no clássico O Pequeno Príncipe, já ironizava o geógrafo que não vai ao campo e apenas toma nota dos viajantes que fazem o trabalho, tem produzido uma imaginação geográfica (SAID, 2007) e uma imaginação espacial (MASSEY, 2008) que, ousamos dizer, combinadas, territorialmente contextualizadas, mas distantes do espaço-limite, produzem o que temos chamado de "decretos de inexistência do lugar transamazônico".

As imagens explicitam a "imagética congelada", mobilizada em livros didáticos, em materiais educativos e mesmo em pesquisas de fôlego sobre o tema que, ao se desvincular da existência que abordam, produzem a repetição segura de uma imaginação oficialmente aceita e, portanto, não contestada, quase infalível ao tratar da Amazônia.

Said (2007, p. 91) demonstra que

[...] essa prática universal de designar mentalmente um lugar familiar, que é "o nosso", e um espaço não familiar além do "nosso", que é "o deles", é um modo de fazer distinções geográficas que pode ser inteiramente arbitrário. Uso a palavra "arbitrário" neste ponto, porque a geografia imaginativa da variedade "nossa terra-terra bárbara" não requer que os bárbaros reconheçam a distinção. Basta que nós tracemos essas fronteiras em nossas mentes; "eles" se tornam "eles" de acordo com as demarcações, e tanto o seu território como a sua mentalidade são designados como diferente dos "nossos".

Não vamos nos ater ao uso devido ou não de conceitos caros aos geógrafos; também não superficializemos o debate que Said levanta, descontextualizando-o. Interessa aqui o paralelo, desenvolvido melhor na próxima sessão, entre o que vivencia o "mundo oriental" que Said explicita face ao "ocidente" que o apreende e; a Transamazônica frente ao conhecimento geográfico produzido sobre esta espacialidade; como é difundido, seja como saber, seja como equívoco ou, até mesmo, inexistência, pelos livros didáticos e, claro, pelos geógrafos que o produzem e os avaliam como "padrão MEC". 
Em uma versão estritamente geográfica, Massey (2008), aprofunda as chamadas imaginações espaciais, visões solidamente reproduzidas que pensam o "outro" como se a nossa espera, vivendo num espaço liso e sem história, enquanto nós, ativos e cheios de histórias, os conquistamos.

Os paralelos com a espacialidade vivida à beira da Transamazônica, podem ser evidentes, porém, é deste "óbvio" que retiraremos uma reflexão desconcertante e, acreditamos, pedagogicamente necessária, não apenas para os professores da educação básica - sempre questionados de maneira injusta por outros, em posição assimétrica na hierarquia educativa institucional (SANCRISTÁN, 2006) - mas, sobretudo, para os doutores.

\section{SENSO COMUM DOUTO}

Bourdieu (2000) levanta a questão da aparente cientificidade e a normatização dos discursos acadêmicos que, muitas vezes, apreendem o senso comum pela mera transcrição deste, travestida de ciência. Ainda desconfio de certa pretensão de ciência, de pureza e coerência inabalável, que o próprio Bourdieu afirma ser preciso perseguir. Porém, mesmo que discordemos em certo nível de Bourdieu, sua crítica em relação ao senso comum douto é válida.

É uma mistura de repetição erudita do conhecimento de superfície e a manutenção desta repetição como realidade ou, mais preocupante, como matriz científica do real! Pois bem, concordamos que as imagens expostas são o que, normalmente, sabemos sobre a Transamazônica, um conhecimento relativamente comum. Entretanto, esta constatação nos leva a duas perguntas incômodas: a) Por que a geografia continua persistindo nestas mesmas imagens espaciais? b) Estas imagens são portas de entrada para revelar realidades efetivas ou escondê-las? O senso comum douto seria a resposta mais imediata para a primeira e, por extensão, está relacionado com a ausência de resposta para a segunda.

Se nossos livros didáticos pretendem uma "iniciação" à compreensão da realidade geográfica brasileira, (trans)amazônica, somos responsáveis pelo saber que acreditamos construir, que normalmente reproduzimos, quase sempre tomamos como verdadeiro sem desconfiar e que é didatizado sem 
autocrítica. O senso comum douto se efetiva como porta para a realidade geográfica aos professores da educação básica e estudantes.

Moraes (2005) aponta a limitação dos estudos que restringem o debate das "ideologias geográficas" aos conteúdos geográficos ensinados, concordamos com ele. Porém, nosso foco central é a educação e seus conteúdos didatizados e chancelados - as editoras estampam um selo "aprovado pelo MEC" em seus livros - que veiculam um tipo de vida no campo amazônico, tendo como especificidade a Transamazônica.

Se é uma limitação não articularmos outros níveis "estruturais", o admitimos; mas nossa escolha se justifica pelo foco na existência dos espaços-limites dos lugares sem encará-los como epifenômenos da estrutura abstraída, como o próprio livro de Moraes, apesar dos méritos, acaba fazendo.

Não falemos aqui dos erros banais e eles existem! (PELUSO, 2006), muito embora as resenhas do Guia...2014 sejam, quase sempre, polidas e elogiosas. Falemos de como não sabemos o que estamos transpondo didaticamente aos estudantes, começando por simples localização:

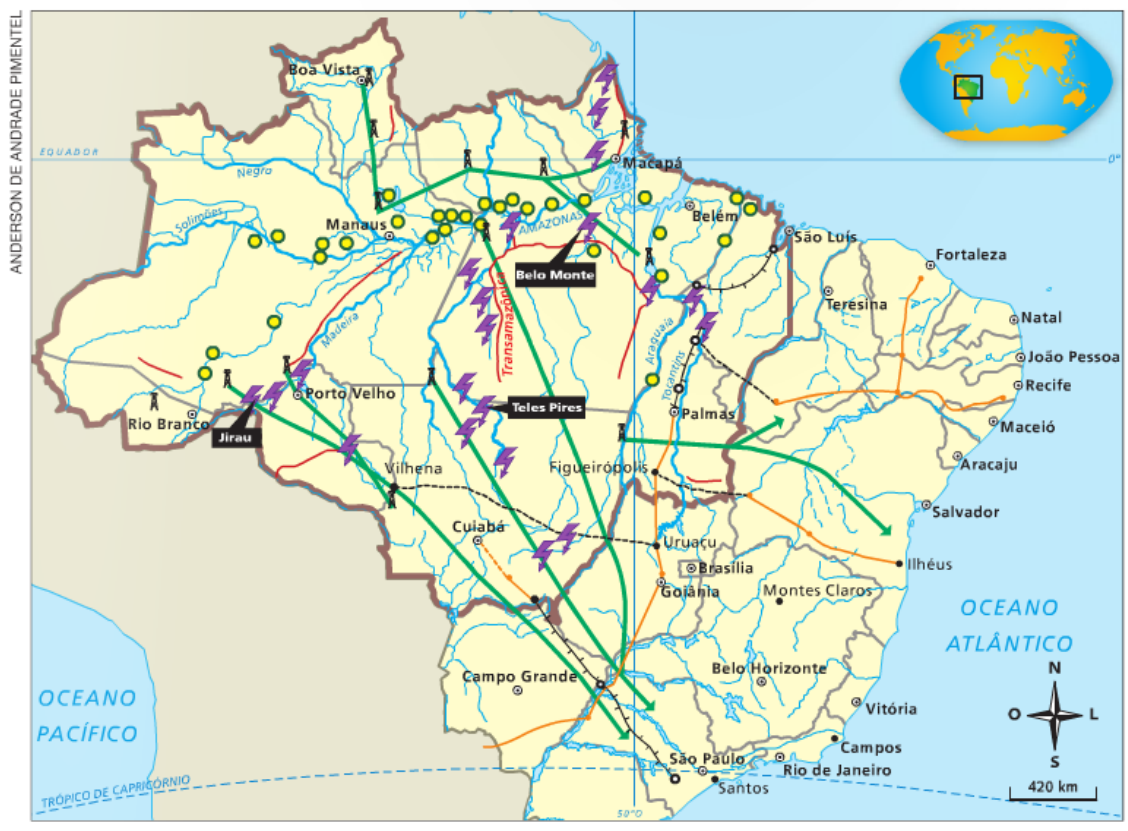

4 Hidrelétricas O Porto e terminais - Rodovias Hidrovias em
operaçăo e planejadas A Transmissăo de energia - Ferrovias já existentes - Ferrovias em construçāo -1
aguardas em estudo licenca au
agbient AMAZÔNIA LEGAL Éoi criado para concentrar as politicas públicas para Composiçáa: 9 estados
(Acre, Amapá, Amazonas, Mato Grosso, Pará, Rondónia,
Roraima, Tocantins e part, do Mrons.

Fonte: Saída pelo Norte vira nova opção ao Porto de Santos. Folha de S.Paulo, 16 out. 2011. Mercado, B6.

Figura 5. A Transamazônica é confundida com a BR-163, os sistemas de engenharia sempre em evidência. Notem que a fonte foi A Folha de São Paulo, o que é muito comum entre livros didáticos. A produção 
cartográfica efetiva, criativa e que evidencia novas dinâmicas ou novos olhares sobre antigas dinâmicas não é uma prática constante, temos uma cartografia de manchetes jornalísticas recorrente nos livros didáticos.

Fonte: Print Screen da p. 91, $7^{0}$ ano, Geografia, Projeto Araribá. Editor Chefe: Fenando C. Verdovate.

Já é estranho que um jornal de circulação nacional como A Folha de São Paulo cometa o equívoco de situar a Transamazônica aonde não é, porém, que o livro didático reproduza o erro, tendo tantas pessoas envolvidas em sua produção, livro este tão amplamente distribuído é temerário, para dizer o mínimo. Ainda que possamos deixar passar como erro tipográfico, está claro que foi mera cópia de um mapa produzido para uma matéria específica. Este problema se junta a outros, como a indução de um tipo de pensamento acerca da Amazônia e as prioridades pensadas para a região, como no caso a seguir, no mesmo livro e contexto:

6 Observe o gráfico a seguir sobre investimentos na Amazônia Legal até 2020.

OS INVESTIMENTOS POR SETOR NA AMAZÔNIA LEGAL

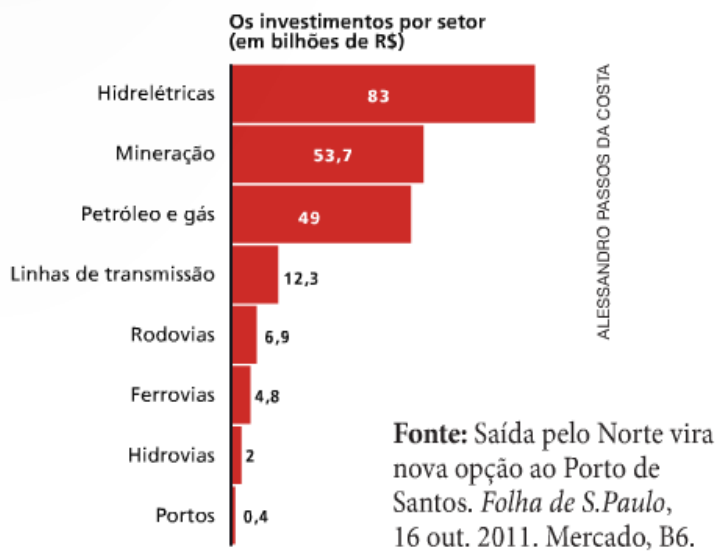

- Quais são os setores que vão receber mais investimentos? Na sua opinião, qual é a importância de se realizar grandes investimentos nesses setores?

Figura 6. Exercício proposto em relação aos investimentos que serão feitos na Amazônia.

Fonte: Print Screen da p. 94, $7^{0}$ ano, Geografia, Projeto Araribá. Editor Chefe: Fernando C. Verdovate.

A pergunta óbvia da criança/jovem morador da zona rural, numa vicinal, pais trabalhadores na lavoura e escola sem merenda, nem tem transporte ou sequer paredes é: aonde está a agricultura e a educação, tia? (supondo que seja uma professora). 
Não vamos aqui questionar se os leitores da Folha de São Paulo querem compreender a Amazônia em sua dimensão utilitarista e externalizada. A questão é se queremos estudantes com imaginação espacial "jornalesca" acerca dos necessários investimentos e quais setores são prioridades para a região. Educação e agricultura (precisamente a familiar e camponesa) não devem entrar na pauta de investimentos estratégicos? Eis a lógica desenvolvimentista ao nível da construção da mentalidade geográfica fundamental!

Podemos afirmar que o professor tem autonomia para orientar um debate mais aprofundando - e realmente tem - só isto nos traz esperança frente ao conteúdo que normalmente lemos sobre como a vida no campo brasileiro e no campo (trans)amazônico em particular, se expressa.

O ensino básico repercute diretamente no superior, numa formação pouco humanista (o que, por definição, deve ser crítica). Naturalmente, os professores formados ou em formação tendem a não levar este debate aprofundado para as salas de aula, um efeito "bola de neve"6.

O termo Transamazônica, ou mesmo a vida à beira das estradas federais, é praticamente ausente, aparece uma vez e sempre ligada à velha crítica ao desenvolvimentismo dos anos 70, no contexto da ditadura militar e dos projetos faraônicos (VESENTINI; VLACH, 2012, p. 167). Embora seja importante frisar que, neste ponto do texto, se faz uma crítica ao uso fragilizado da navegabilidade dos rios na região, priorizando as estradas.

É possível levantar a questão douta (e já foi levantada, omitiremos sua autoria por questões éticas): “e qual a importância da Transamazônica para ser tema em livros didáticos na parte que discute Amazônia?" Mesmo que uma estrada federal que foi (e ainda é, vide a Hidrelétrica de Belo Monte) central ao processo de ocupação recente de toda uma região, não seja importante... a Transamazônica é um caso emblemático de como nossa "imaginação geográfica" reduz a vida - de milhões de migrantes e moradores que vivem à beira de estradas - ao objeto técnico no debate geográfico.

\footnotetext{
${ }^{6}$ Credito este argumento à Luana Nunes Martins de Lima, e aproveito para agradecê-la pela leitura crítica da primeira versão do artigo
} 
Na referida coleção (Teláris) assinada por Vesentini e Vlach (2012), vemos as sutilezas de uma mudança do pensamento sem uma efetiva renovação empírica, o que fragiliza a própria concepção teórica autodenominada crítica.
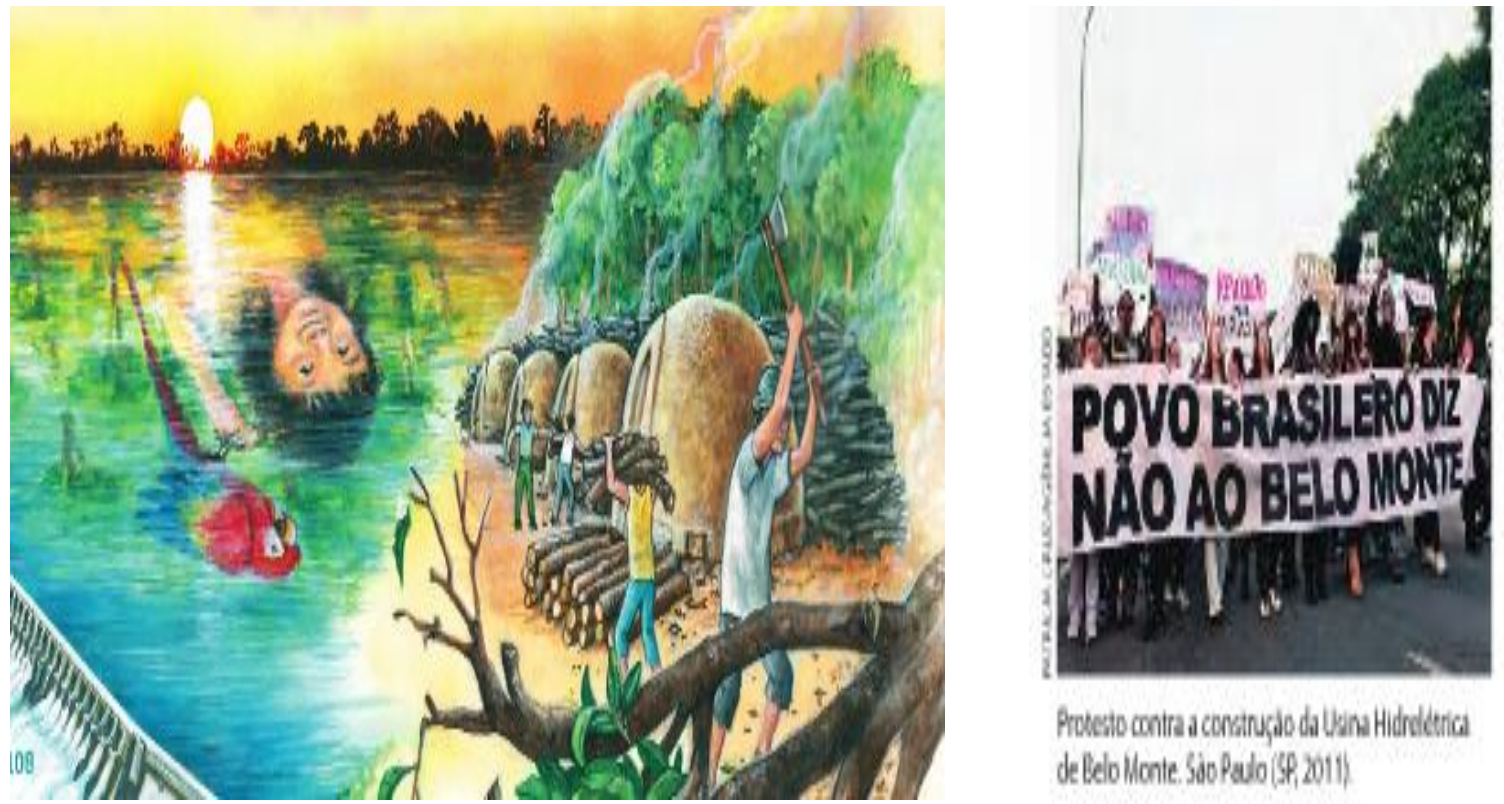

Figuras 7 e 8. Após um texto tocante sobre a questão dos usos do espaço amazônico e suas potencialidades, temos a imagem à esquerda e, na outra página, o exercício referente ao texto, que expõe o caso da usina hidrelétrica de Belo Monte, no rio Xingu, em Altamira, temos a imagem da direita (a legenda da imagem diz: Protesto contra a construção da Usina Hidrelétrica de Belo Monte. São Paulo, 2011.

Fonte: Print Screen pp. 108-109, Projeto Teláris, Geografia, $7^{0}$ ano, autores: José Willian Vesentini e Vânia Vlach, 2012.

As imagens tendem a reforçar algumas impressões sempre revividas em relação à região: os trabalhadores locais, destruindo a floresta para fazer carvão, ou por ignorância, seja por que são mandados (nunca se diz exatamente por quem ou por quais demandas), os indígenas assistem passivos e tristes o desmatamento, paralisados, quase divindades da floresta que contemplam o mundo, mas quem realmente age e luta é o "povo brasileiro" que, segundo a própria imagem, se encontra em São Paulo! 
Nahum (2012), ao discutir os Planos de Desenvolvimento da Amazônia (PDAs), aponta para as representações construídas que aprisionam a região em um modelo de realidade que não é real, mas que se efetiva enquanto tal, por força do plano. Este modelo pode ser, grosso modo, definido por algumas características: a) o homem [e a mulher, normalmente esquecida, nos primeiros planos] são apenas um número (população), quando aparecem enquanto como seres ativos, são agentes destruidores da floresta; b) A Amazônia assume a centralidade de um sujeito, e não resultado e condição para a construção humana; c) as diferenciações internas são apagadas, de modo que se compreende a Amazônia como um espaço homogêneo; d) A natureza é um recurso a ser dominado e explorado; e) as diferenciações humanas são subestimadas e, efetivamente, ignoradas.

Acrescentaríamos aqui, consubstanciando a proposição de Nahum (2012) que: 1. As populações tradicionais são percebidas como passivas, esperando o desenvolvimento chegar para mudar suas vidas, paralisadas no tempo e sem dinamismo espacial; 2. Os processos de contestação tendem a ser vistos como uma tomada de consciência de fora, do mundo, do país, do povo brasileiro; não dos próprios amazônidas e, sobretudo, dos amazônidas que vivem no espaço do campo; 3. A urbanização se coloca como chave para o desenvolvimento, bem como a industrialização correlata; 4 . 0 progresso gera efeitos colaterais inevitáveis, que precisam ser minimizados com uma "sustentabilidade" alternativa, técnica e cientificamente produtiva e afinada com o mercado, na qual o sentido de desenvolvimento não é questionado, muito menos repensado.

Tais ideias, que juntas perfazem um ethos, uma imaginação geográfica e espacial (SAID, 2007; MASSEY, 2008), não são restritas ao planejamento de Estado para a Amazônia, atravessa, enquanto trajetória constitutiva portadora de uma intencionalidade, o processo educativo. Este, geopoliticamente pensado, para configurar uma dada visão, muito difícil de questionar porque muito coerente na sua construção e, sobretudo, porque produzida, avaliada e rubricada por geógrafos que se destacam no ato de pensar o Brasil, o território, os lugares, as regiões, a própria educação geográfica em perspectiva crítica. 
A Amazônia, sobretudo no texto do livro Expedições Geográficas (ADAS, M; ADAS, S., 2011), é fatiada em quadros - natural, econômico, social - e elevada ao estatuto de ser, ente, com vontade própria ou com sua vontade controlada por agentes externos.

Os livros estabelecem uma aproximação ao que Kosic (2005) chamou de pseudoconcreticidade, mundo das representações fetichizadas, porém, nos parece que a saída não é exatamente a totalidade (KOSIC, 2005; SARTRE, 2002; SANTOS, 2004), como se esta fosse apreensível pela construção meticulosa de um "modelo dinâmico" que capturasse as relações mais fundamentais de uma dada estrutura(ação) e as explicasse em sua pura verdade desnuda. Não, a saída é justamente o inverso, mergulhar na lugaridade efetiva do mundo da vida, tematizado por tais representações, para construir uma radicalidade que dialetize o Mundo da Vida e o Mundo do Sistema (HABERMAS, 2012); e daí compreendermos a instabilidade da dialética (MERLEAU-PONTY, 2012) na interpretação dos fenômenos que são simplificados por um tipo de dialética amarrada, controlada, utilizável e utilitária, vendida como verdade nos livros didáticos e aprovada por eminentes geógrafos.

\section{ENTRE ESCALAS - MORTE DO VIVER?}

Sempre é possível defender a cientificidade que produz o saber e os processos de didatização que comunicam tal saber. É evidente a importância de um instrumento como o Guia de Livros Didáticos, bem como processos de avaliação que garantam a correção de distorções graves na comunicação da espacialidade geográfica brasileira e global, sobretudo, no processo de formação educativa fundamental e média.

Também é evidente a dificuldade de realizar uma discussão regional - e do lugar - mais aprofundada, que seja ao mesmo tempo significativa, não simplista e incluí-la aos livros didáticos, para turmas de $7^{0}$ ano e que tenham capacidade de dialogar com os estudantes dos mais distantes lugares do Brasil. 
Aqui a questão de escala revela sua força e, estranhamente, a fraqueza com que a enfrentamos, porque é preciso um esforço teórico e didático para fazer esta trajetória do geral (território) ao específico (lugar), passando pelo particular (região), e manter uma unidade do discurso acerca do saber.

Essa dificuldade é defensável e coerente, mas justamente por isto é inaceitável - se não conseguirmos criar maneiras de transposição do saber geográfico que avance no entendimento sobre o território, ao alcance de estudantes em formação que, seguramente, não serão geógrafos, mas têm o direito de compreender a complexidade escalar do território que vivem - para que serve e, sobretudo, para quem serve o saber que criamos? Um saber cada vez mais distanciado do real, ou da realidade, para não ferir os mais exigentes ouvidos.

Quando falamos das populações que vivem nos espaços rurais amazônicos e que usam os mesmos livros didáticos do PNLD e do Guia, essa distância não é apenas conceitualmente evidente, ela é existencial!

Soma-se a justificativa escalar, duas outras, também coerentes e defensáveis - a cognição e a urbanidade inescapável. Não cabe aqui discuti-las, só tenhamos em mente que a cognição aponta para um nível de desenvolvimento específico e detectável dos estudantes em relação a suas idades, o que deveria delimitar o que pode ser ensinado ou não, mas que deveria ser pensado em como pode ser ensinado ou não; a urbanidade incontornável anuncia que é o mundo que já vivemos (SOUZA, 2006).

Nesse mundo o campo é um apêndice prestes a ser cortado. Embora haja questionamentos, cada vez mais ponderamos sobre esta tendência irrevogável e esta argumentação urbanocêntrica (HAGE, 2005) que torna o campo um passivo, tecnicamente menos denso, uma pretendida extensão da urbanidade no âmbito de uma revolução urbana virtual (LEFBVRE, 1999) hoje, apressadamente, já efetivada (OLIVEIRA, 2010), dirigindo um pensamento que canibaliza o campo e a vida para conformá-la a uma tipologia cujo centro da rede, na Amazônia, só pode ser o urbano (TRINDADE JR., et al., 2011).

Arbitrariedade do pensamento que controla a dialética em modelos explicativos e não interpretativos, abstraídos e não vividos no calor da existência humana. Ao que nos consta, a vida, inclusive coletiva e 
socialmente espacializada, pode se articular em outras redes que, embora não desprezem as cidades, não são sugadas para o "buraco-negro" urbano como gados ao matadouro, aí o resíduo lefbvreano deveria ser mais radicalizado, para pensar o campo e a vida no campo, mas deixemos isto para os dialeticamente comportados pensarem.

Poderíamos sugerir leituras contestadoras desta perspectiva, desde as mais estatisticamente fundamentadas (VALADARES, 2014), até as humanamente engajadas (HAGE, 2005). Entretanto, confrontemos esta geopolítica brasileira da imaginação geográfica ao Mundo da Vida (HUSSERL, 2012), não a partir de uma atitude ingênua, mas a partir da perspectiva existencial, evidenciando a geograficidade (DARDEL, 2011).

A geografia, antes de reflexão cientificizada é ato, é uma realização humana que evidencia um fenômeno básico da existência, inclusive da existência refletida - como arte, ciência ou outro saber - a espacialização experimentada e criada pelos seres humanos!

Se numa ponta estamos nós, acostumados a vampirizar grupos sociais em sua espacialidade vivida, mamiferos de luxo chamados a legislar sobre o que deve ser ensinado e que tipo de guia devemos oficializar, quase sempre estamos distantes da vida amazônica, ainda mais da vida no campo amazônico e, como se já não fosse o bastante, quase desconectados com a vida transamazônica.

Em bases de dados amplamente disponíveis é possível realizar uma pesquisa elementar, atualizada e com conteúdos bastante interessantes sobre a realidade transamazônica, ainda que, restringindo ao campo geográfico, a quantidade e qualidade das pesquisas seja reduzida. Entretanto, o fato é que, a partir de outros campos do saber - notadamente a antropologia, a sociologia, a ciência política e a educação - é possível constituir uma temática didaticamente acessível do ponto de vista de geografia

\footnotetext{
${ }^{7}$ Termo corretamente empregado por uma professora no SINGA 2013, no espaço de diálogo sobre educação do campo, que designa a ação de pesquisadores que alavancam seus currículos e ganham prestígio nas universidades ao custo de comunidades que continuam exatamente do mesmo jeito e até precarizam sem que haja qualquer mobilização do cientista na relação com a comunidade. Aqui, pelo visto, a noção positivista de "distanciamento do objeto" é espertamente mobilizada.
} 
que se ensina, sem cair na repetitividade da imaginação geográfica com a etiqueta de crítica, o que não o é.

Estamos decretando a inexistência da vida à beira da Transamazônica, como pensadores do espaço amazônico, estamos assumindo um compromisso - negação de milhares de famílias que produzem uma geografia em ato (DARDEL, 2012) e não se reconhecem na geografia dos livros que afirmam contar, de maneira crítica, a (trans)amazônica. E não sejamos ingênuos, alguém ganha com este decreto de inexistência justificado pelo pensamento científico e educativo.

Em grupos focais de discussão, realizados em Janeiro e Julho de 2013, as falas das professoras são reveladoras:

Os livros falam muito de grandes cidades, de São Paulo, de Rio de Janeiro, muito pouco de nossa região (Professora Elieth Silva, Julho de 2013).

Tem o conteúdo lá e temos que dar conta dele, a coordenação pedagógica nos cobra isso, aí ficamos nos livros (Professora Alzenaide N. S. Porto, Julho de 2013).

Em alguns momentos saímos dos livros, nas festinhas da escola, nas datas comemorativas, trabalhamos outras coisas, com materiais e coisas daqui, mas só nestes momentos, porque é difícil, não é simples pensar isto com o multisseriado (Roseane Marçal de Lima, Fevereiro de 2013).

Quando chegou o material da Escola Ativa (programa nacional que visa melhorar a qualidade das escolas multisseriadas do Campo através de diversas estratégias pedagógicas), os professores daqui da cidade [Pacajá] ficaram com todo o material, porque a Secretaria Municipal determinou um dia para todos pegarem, mas nós que trabalhamos no campo e distante nem ficamos sabendo (Professora Maria Bastos, Fevereiro de 2013).

As relações assimétricas - cidade e campo - persistem no acesso ao material didático diferencial; soma-se a isto, a ambiguidade que o livro se torna nestas realidades, de um lado o único material didático disponível, por outro lado os que vivem o campo à beira da Transamazônica não se reconhecem nele e não conseguem superá-lo, salvo em momentos pontuais, não amparados pelas secretarias municipais e/ou diretorias das escolas.

Não é apenas uma questão de não se reconhecer - é o tipo de indução que o livro didático pode repercutir, como na fala a seguir:

Já vem pronto o plano de aula, né? Então copiamos muito do que tá no livro, facilita o nosso trabalho, temos que entregar, é uma exigência, mas muita coisa dali a gente não usa ${ }^{8}$.

\footnotetext{
${ }^{8}$ Professora L.P. S., Fevereiro de 2013. Neste caso, omitimos o nome por uma questão de ética para com a docente.
} 
Essas coisas não se podem falar em sala de aula, é cutucar onça com vara curta, vemos muita coisa, mas temos que ir fazer nosso trabalho certinho e fingir que não vemos [docente do campo falando sobre os conflitos de terra, as desigualdades, que não entram no debate geográfico das escolas $]^{9}$

Copiar os planos de aulas já inscritos nos livros se tornou uma prática, dada exigência das coordenações pedagógicas em relação ao cumprimento do conteúdo do livro - copiar para entregar oficialmente e não usar de fato! Ambiguidade que, em si, é potencialmente dialética: não usar significa tanto rebeldia diante da oficialidade e, ao mesmo tempo, diante do que está nos livros; porém, não usar revela a dificuldade de adaptar o conteúdo à realidade do lugar. Realidade extrema, como a segunda fala revela, realidade que os livros anunciam lateral e genericamente, descomprometidos com as realidades, mais interessados em cumprir as normatizações "padrão MEC".

Ambiguamente também, o livro didático é superestimado, em função das carências variadas nas escolas no campo, que não podem ser efetivamente "escolas do campo",

[que] busca[m] cultivar um conjunto de princípios que devem orientar as práticas educativas que promovem - com a perspectiva de oportunizar a ligação da formação escolar à formação de um postura na vida, na comunidade - o desenvolvimento do território rural, compreendido este como espaço da vida dos sujeitos camponeses [...]. [as escolas são] protagonista[s] na criação de condições que contribuam para o desenvolvimento das comunidades camponesas, desde que se promova no seu interior importantes transformações tal qual já vem ocorrendo em muitas escolas no território rural brasileiro, que contam com o protagonismo dos movimentos sociais na elaboração de seus projetos educativos e na sua forma de organizar o trabalho pedagógico (MOLINA; SÁ, 2013, p. 327).

Concordando com Molina e Sá (2013), temos clareza que a escola do campo é um projeto, e como tal, deve ser posto em movimento no acontecer, na vivência cotidiana dos grupos de trabalhadores rurais que almejam para seus filhos uma escola: ponte para futuridade, como registramos em diversas conversas com pais de estudantes que vivem na "zona rural"10. Enquanto projeto, sua existência se dá no enfrentamento cotidiano em espaços-limite, os lugares aonde o acontecer humano se defronta com o

\footnotetext{
${ }^{9}$ Professor D. C., docente na sede municipal em Anapu, mas que trabalha na "zona rural", entrevista realizada em Fever eiro de 2014.

${ }^{10}$ Pesquisa em andamento ligada ao projeto de doutoramento, mas também falas explícitas no documentário produzido por nós: À Beira da Faixa (30 min.), em parceria com a SEDUC-PA/FADESP/FCC, 2013.
} 
fracasso e a liberdade, a partir de posicionalidades coletivas e pessoais diante das condições mortalmente desiguais (PANTOJA, 2014), jamais capturadas nos livros.

Queremos dizer com isso que os livros deveriam funcionar como documentos da realidade, como testemunhas de seu tempo e espaço, como dinamizadores dialógicos das existências entre lugares, entre pessoas que partilham coexperiências sem viverem copresenças e, ao mesmo tempo, explicitar a diversidade incontornável da experiência do espaço - não em uma visão genérica e repetitiva: o negro, o índio, o urbano, o rural, o homem, a mulher, mas em sua evidência problematizadora das condições de vivência - um documento de vontade de mudança, vontade partilhada entre diferentes.

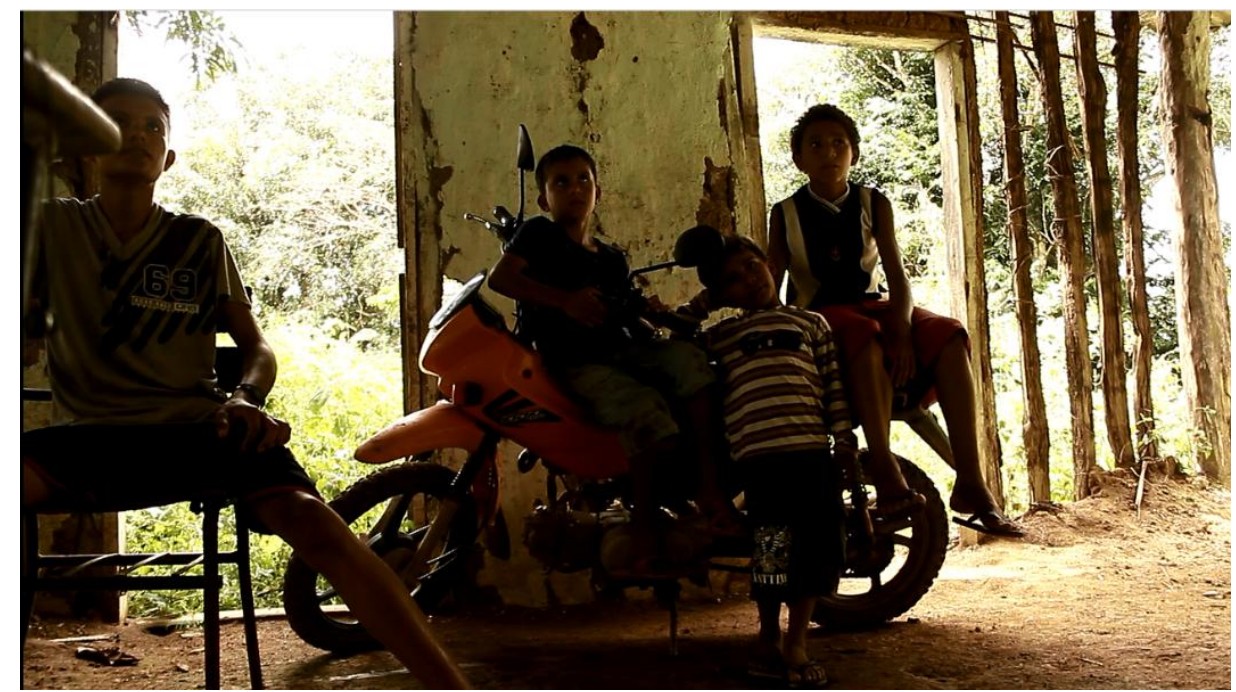

Figura 9. Still da filmagem realizada em Maio de 2013, em entrevistas com pais e estudantes numa das vicinais (estrada menor que sai da Transamazônica para dentro da floresta).

Fonte: Matheus Moura.

A escola sem paredes, as crianças sem carteiras, nessa carência o livro repercute ilusões e sonhos, os autores dos mesmos deveriam ter esta dimensão para criar outro tipo de comprometimento com a existência que pretendem esclarecer.

\section{CONSIDERAÇÕES AO FIM DA ESTRADA?}

Evitando o atomismo demasiado em nossa pesquisa, o desafio está posto, romper com a imaginação sustentada que ganha corpo de verdade incontestável. Apontamos, primeiro, para a necessidade de 
reconhecer que pouco ou quase nada sabemos das realidades transamazônicas, via guia ou manual, sala de aula, livros didáticos, revistas e jornais, sem uma geograficidade como base para ação comunicativa, é falar do que não se conhece e transmitir o que não viu, vivenciou, sentiu ou experimentou.

Segundo, contestar com veemência a perpetuação dos resultados obtidos há décadas como verdades científicas permanentes, para criar uma transposição didática que problematize a contemporaneidade das vidas à beira das estradas, não apenas dos fluxos, dos objetos e dos centros. E terceiro, questionar a supremacia pedagógica de alguns sobre muitos, de geógrafos que estando distante de uma realidade específica pensam saber mais dela do que aqueles que vivem sua complexidade diária.

Em se tratando da Amazônia e, em "maior escala", Transamazônica, isso não é diferente. Existe no cenário didatizado (e recomendado por geógrafos com autonomia de pensamento) que nega a existência do lugar como categoria, espaço-limite; substituído por um lugar como conceito, alimentando um acervo imaginário destituído de imaginação em sua mesmice, quando muito um procedimento metodológico, distante do viver dos que possuem poucas opções ou quase nenhuma. Esta negação não só limita as vozes de quem vive no espaço-limite no ato de criar conexões escalares, como impede os que estão em outros lugares e variadas escalas ouvirem/lerem, porque não reconhecem a existência do grito, do desabafo, do choro, do sorriso, da vida, sem elo de linguagem, morre assim o viver.

Não pensamos que apartar as realidades do campo e da cidade vá resolver a problemática, criando um tipo exclusivo de educação, porém, a Educação do Campo deve lutar pelo espaço de autonomia pelo qual seus representantes e protagonistas vêm lutando, porque pode contribuir para questionar a própria dinâmica de feitura dos livros didáticos - em escritórios editoriais nos grandes centros urbanos do eixo Rio-São Paulo - em prol de uma ação comunicativa (HABERMAS, 2012) mais lugarizada, mais "pé no chão" e mais participativa, ou pelo menos mais honesta na admissão do fraco diálogo com os professores, estudantes e realidades do campo transamazônico, aqui referido como um espaço particular, mas potencialmente relacionável a outros contextos (MERLEAU-PONTY, 2012). 
Uma geografia, enquanto discurso de saber, precisa evidenciar e repercutir esta realidade; precisa assumir uma cartografia da vida concreta, precisa chocar-se contra o modelo padronizado e comportado que assegura, de um lado, ganhos de prestígio, financeiros; e, de outro, decreta inexistências, produz irreconhecimento, desconhecimento, harmonização da realidade ou, no máximo, o confronto de duplos genéricos (os de dentro e os de fora; os antigos e os novos, etc.), uma dialética raquítica que não admite sua incapacidade de estabelecer comunicação didática com a realidade que diz capturar.

\section{REFERÊNCIAS}

ADAS, M.; ADAS, S. Expedições Geográficas - 7oano. São Paulo: Moderna, 2011.

ANGOTTI-SALGUEIRO, H. A construção de representações nacionais: os desenhos de Percy Lau na Revista Brasileira de Geografia e outras "visões iconográficas" do Brasil moderno. Anais do Museu Paulista. 2005, vol.13, n.2, pp. 21-72. Disponível em: http://www.scielo.br/pdf/anaismp/v13n2/a03v13n2.pdf, acesso em 20.06.2014.

BOURDIEU, P. o Poder Simbólico. Rio de Janeiro: Bertrand Brasil, 2000.

DARDEL, E. 0 Homem e a Terra. Natureza da Realidade Geográfica. São Paulo: Perspectiva, 2011..

Habermas, J. Teoria do Agir Comunicativo. Racionalidade da Ação e a Racionalização Social \& Sobre a Crítica da Razão Funcionalista. vol. 1-2. São Paulo: WMF Martin Fontes, 2012.

HAGE, S. M. Desafios da educação rural no Estado do Pará/Região Amazônica. In: HAGE, S. M. (Org.). Educação do Campo na Amazônia. Retratos de Realidade das Escolas Multisseriadas no Pará. Belém: Gráfica e Editora Gutemberg, 2005.

JASPERS, K. Filosofia. Tomos I e II. Madrid: Universidade de Puerto Rico, 1958.

Introdução ao Pensamento Filosófico. São Paulo: Cultirx, 2011.

LEFBVRE, H. A Revolução Urbana. Belo Horizonte: Ed. UFMG, 1999.

MASSEY, D. Pelo Espaço. Rio de Janeiro: Bertrand Brasil, 2008.

MOLINA, M; SÁ, L. M. Escola do Campo. In: CALDART, R. et. all. (Orgs.) Dicionário de Educação do Campo. $3^{\text {a }}$ ed. Rio de Janeiro, São Paulo: Escola Politécnica de Saúde Joaquim Venâncio, Expressão Popular, 2013.

KOSIC, K. Dialética do Concreto. São Paulo: Paz e Terra, 2002.

MERLEAU-PONTY, M. o Visível e o Invisível. São Paulo: Perspectiva, 2012.

MOARES, A. C. R. Ideologias Geográficas. Espaço, Cultura e Política no Brasil. São Paulo: Annablume, 2005. 
NAHUM, J. S. Região e Representação: A Amazônia nos PDAs. In: Geocrítica, v. XVII, n. 985, 2012. Disponível em: http://www.ub.edu/geocrit/b3w-985.htm, acesso em 12.05.2014.

OLIVEIRA, M. P. Espaço e política - tecendo o espaço público na sociedade urbana contemporânea. La planificación territorial y el urbanismo desde el diálogo y la participación. Actas del XI Coloquio Internacional de Geocrítica, Universidad de Buenos Aires, 2010. Disponível em: www.filo.uba.ar/contenidos/investigacion/institutos/geo/geocritica2010/668.htm acesso em 20.08.2014.

PANTOJA, W. W. R.; CORDEIRO, R. C. Transamazônica como referência socioespacial no processo de formação de professores. In: Anais do VI Encontro da ANPPAS, Belém, 2012. Disponível em: http://www.anppas.org. br/encontro6/anais/ARQUIVOS/GT6-1487-1410-20120715235629.pdf. Acesso em 20.06.2014.

PANTOJA, W. W. R. (Trans)amazônica e educação: imaginações espaciais e negação do ser. Anais do VII CBG. Vitória, 2014. Disponível em:

http://www.cbg2014.agb.org.br/resources/anais/1/1404697538_ARQUIVO_artigocongressobrasileirodegeografia_Transa mazonica_.pdf, acesso em 16.02.2016.

RODRIGUES, S. B.; CARRIERI, A. P.; LUZ, T. R. Competição Organizacional: Bricolagem Simbólica e seus Significados para os Gerentes. In: EnANPAD 1999. Disponível em

http://www.anpad.org.br/diversos/trabalhos/EnANPAD/enanpad_1999/ORG/1999_ORG5.pdf, acesso em 17/08/2014.

SAID, E. W. O Orientalismo. O Oriente como Invenção do Ocidente. São Paulo: Companhia das Letras, 2007.

Cultura e Imperialismo. São Paulo: Companhia das Letras, 2011.

SAINT-EXPÉRY, A. o Pequeno Príncipe. Rio de Janeiro: Agir, 2006.

SACRISTÁN, G. J. Tendências investigativas na formação de professores. In: PIMENTA, S. G.(org.). Professor Reflexivo no Brasil: gênese e crítica de um conceito. $4^{\text {a }}$ ed. São Paulo: Cortez, 2006.

SANTOS, M. Por uma Geografia Nova. São Paulo: Edusp, 2002.

. A Natureza do Espaço. Técnica e Tempo. Razão e Emoção. São Paulo: Edusp,

2004.

SOUZA, M. L de. A Prisão e a Ágora - reflexões em torno da democratização do planejamento e da gestão das cidades. Rio de Janeiro: Bertrand Brasil, 2006.

SPOSITO, M. E. S. (Org.) Livros Didáticos de História e Geografia. Avaliação e Pesquisa. São Paulo: Cultura Acadêmica Editora, 2006.

TRINDADE Jr., S. C. C. Espacialidades e temporalidades urbanas na Amazônia ribeirinha: mudanças e permanências a Jusante do rio Tocantins. In: Acta Geográfica, ed. esp., 2011. Disponível em: http://revista.ufrr.br/index.php/actageo/article/viewFile/544/607, acesso em 21.08.2014.

VALADARES, A. A. O Gigante Invisível: território e população rural para além das convenções oficiais. In: Texto Para a
Discussão
IPEA.
Brasília:
IPEA,
2014.
Disponível
em:

http://www.ipea.gov.br/portal/images/stories/PDFs/TDs/td_1942.pdf, acesso em 19.06.2014.

VERDOVATE, F. C. (Editor). Geografia 7º ano. Projeto Araribá. 3ª ed. São Paulo: Moderna, 2010.

VeSEnTini, J. W.; VLACH, V. Geografia 7º Ano. Projeto Teláris. São Paulo: Ática, 2012. 
WEBER, M. Economia e Sociedade. v. 1-2. Brasília: Editora UNB, 2012. 